\title{
Fondos de Guerra Civil y Posguerra en la Sección Fondos Contemporáneos del Archivo Histórico Nacional
}

\author{
Jesús GaITE
}

\section{LA SECCIÓN DE FONDOS CONTEMPORÁNEOS}

Surgió en los años sesenta de este siglo, para hacerse cargo de la documentación histórica contemporánea, almacenada en diversos departamentos ministeriales y en trance de posible desaparición a falta de un Archivo Intermedio, como el que ahora existe en Alcalá de Henares.

Ministerios y Tribunales de Justicia fueron los principales usufructuarios de esta nueva sección del Archivo Histórico Nacional, en donde confluyeron fondos importantes del período de Guerra Civil y aun posteriores, como el fondo de la Causa General y el remitido por la Dirección General de Policía a partir de mil novecientos ochenta y seis.

Algunos fondos que aquí describiremos, como el de la Caja General de Reparaciones, venían camuflados, por decirlo así, dentro de los 24.000 legajos enviados por el Ministerio de Hacienda y ha habido que irlos entresacando pacientemente para formar el Inventario que hoy anunciamos ya como terminado y a disposición de los investigadores; otros esperan una tarea semejante de identificación y descripción como los fondos correspondientes a la Comisión liquidadora de Campsa-Gentibus, CEA y CLUEA que después explicaremos. Otros fondos por fin, no están en este momento en la sección de Contemporáneos sino en la Sección de Diversos, formando parte de los archivos personales allí depositados, pero que se mencionan por ser de la época que nos ocupa.

\section{FONDOS PROCEDENTES DE LA ADMINISTRACIÓN DE JUSTICIA}

\section{El fondo de la Audiencia Territorial de Madrid}

Este organismo, hoy convertido en Tribunal Superior de Justicia, envió al Archivo Histórico Nacional, en los años setenta, cerca de cuatrocientos 
legajos de materia penal que abarcan desde 1900 a 1940. Aproximadamente un tercio de estos legajos se refieren a procedimientos tramitados durante la Guerra Civil, casi todos referidos a Madrid y su provincia. Delitos como el secuestro, la muerte violenta, las desapariciones, los hallazgos de cadáveres, las publicaciones clandestinas, los daños por explosión y el espionaje son demasiado frecuentes en un Madrid marcado por los odios personales y la violencia política de la que son expresión los expedientes judiciales aquí citados.

Conviene advertir que no se incluyen en este fondo los expedientes incoados por los Tribunales populares, desde su creación en agosto de 1936, y que fueron ampliando sus competencias hasta comprender una gran parte de los delitos de carácter penal, atribuidos antes a las Audiencias Territoriales. Estos expedientes fueron recogidos en el año 1940 e incluidos en el Archivo de la Causa General, para estudiar las actuaciones judiciales en la zona republicana durante la Guerra Civil.

De todos modos el fondo judicial que se conservó en la Audiencia Territorial de Madrid y se transfirió al Archivo Histórico Nacional no deja de ser importante, sobre todo para el último año de guerra, pues el decreto de la República de 24 de marzo de 1938 devolvía a las Audiencias Territoriales una gran parte de la jurisdicción penal en detrimento de los Tribunales populares.

\section{El fondo de la Causa General}

En septiembre de 1980 se reciben en el Archivo Histórico Nacional, procedentes de la Fiscalía General del Estado cerca de 4.000 cajas, que guardan documentos correspondientes a la "Causa General", instruida para averiguar «los hechos delictivos cometidos en todo el territorio nacional durante la dominación roja" (Decreto de 26 de abril de 1940). La investigación de estos sucesos duró prácticamente hasta 1960, y tuvo como resultado una acumulación de datos informativos de enorme interés para el conocimiento de todo lo sucedido en los tres años de nuestra cruenta guerra civil (1936-1939).

Un análisis de los documentos permite establecer tres grandes grupos o series que vamos a analizar separadamente.

\section{A) Causa General Informativa}

Son los resultados de la investigación, ordenada por el Decreto de 26 de abril de 1940, y que recogen en cada provincia un análisis de los hechos 
delictivos cometidos a partir de las elecciones de febrero de 1936. La documentación se subdivide en once piezas, que se describen a continuación, y un informe del Fiscal Instructor.

Pieza primera o principal: Informa sobre los delitos cometidos en la capital y en cada uno de los pueblos de cada provincia: personas muertas o desaparecidas, cadáveres recogidos, torturas, incendios y saqueos de edificios y de iglesias... Incluye abundantes declaraciones de testigos y denuncias de los perjudicados.

Pieza segunda: Del Alzamiento Nacional: Informa sobre la actuación del ejército republicano y del de liberación, incluyendo referencias a los juicios sumarísimos ante los tribunales militares republicanos, y a la participación de los civiles en estos sucesos del 18 y 19 de julio de 1936.

Pieza tercera: Cárceles o sacas: Reúne los informes sobre directores y guardianes de cárceles, mencionando también las personas encarceladas por razones políticas, el trato que recibieron, y los presos que fueron ejecutados sin mediar sentencia de un tribunal de justicia.

Pieza cuarta: Checas: Recoge todas las diligencias practicadas para averiguar la existencia de las mismas, y la organización y funcionamiento de las Patrullas ciudadanas de Control y las actuaciones del Servicio de Investigación Militar (S.I.M.).

Pieza quinta: Justicia Roja: Contiene relación de magistrados y jueces, fiscales, secretarios y listas de jurados que actuaron en los tribunales populares. Se adjuntan abundantes expedientes de actuación de los Tribunales Populares: procedimientos, penas de muerte e informes médico-forenses sobre levantamiento de cadáveres y autopsia de personas asesinadas.

Pieza sexta: Prensa Roja: Examina las colecciones de periódicos de cada provincia, durante el dominio republicano, y los folletos de propaganda publicados, con mención de los directores, de los autores de articulos y una mención de la orientación política de los mismos.

Pieza séptima: Actuación de las autoridades gubernativas locales: Recoge informes de los principales organismos de la Administración Central Periférica (Guardia Civil, Comisarías de Policía, delegaciones de Hacienda, Jefaturas de Obras Públicas, etc.), acerca de la actuación de los representantes del Gobierno central, mientras duró la dominación del gobierno republicano.

Pieza octava: Delitos contra la propiedad: Refiere casos de incautación de tierras, industrias u otras propiedades, control obrero o colectivización 
de las mismas. Las Cámaras provinciales de Industria y Comercio, Cámaras Agrarias y Cámaras de propiedad informaron sobre las denuncias recibidas de los perjudicados por estos delitos.

Pieza novena: Banca: Recoge los informes de los Bancos y Cajas de Ahorro de cada provincia relativos a los atropellos al derecho de propiedad de los mismos o efectuados contra sus depositarios, cuentacorrientistas o arrendatarios de cajas de alquiler. Igualmente se informa sobre las emisiones de billetes realizadas por el banco y los empréstitos del mismo.

Pieza décima: Persecución religiosa: Sacerdotes y religiosos asesinados y conventos destruidos o profanados. El Provisor de la Diócesis se encargaba de suministrar estos informes.

Pieza undécima:Tesoro artístico y cultura roja: Recoge los daños sufridos por el Tesoro artístico en cada provincia y la situación de la enseñanza en territorio republicano, con relación de los profesores que la impartían.

Informe-resumen del Fiscal Instructor: Elevado a la Inspección de la Causa General, con los resultados obtenidos en las diversas piezas.

Conviene advertir que no en todas las provincias se desarrolla esta investigación con la misma intensidad, sobre todo si se tiene en cuenta que muchas de ellas estuvieron desde muy pronto en manos de las tropas de Franco ${ }^{1}$.

\section{B) Documentos del Gobierno e Instituciones republicanas}

Se incorporaron al Archivo de la Causa General como pruebas de la investigación iniciada en abril de 1940; pero en realidad constituyen un riquisimo arsenal de la actividad de las instituciones y gobierno republicano, en una época de la que faltan noticias fidedignas, por haberse perdido durante la guerra, un inmenso acopio de documentos. Varias son las subseries que se han establecido:

Documentos del Tribunal Popular de Responsabilidades Civiles: Establecido para fijar las cuantías pecuniarias y el alcance de las incautaciones

1 Las provincias de Madrid y Barcelona son las que poseen una información más exhaustiva. El Archivo Histórico Nacional tiene a disposición de los investigadores un inventario analítico, recientemente mecanografiado que se titula: "Cataluña durante la Guerra Civil. Documentos procedentes del Archivo de la Causa General (1934-1960)", 141 páginas y abundantes indices. Redactado por Elena Rodriguez-Magallanes bajo la dirección de Jesús Gaite Pastor. 
a las personas que apoyaron el levantamiento militar del 18 de julio. Años: 1936-39.

Tribunal especial de Espionaje y Alta Traición: Establecido para castigar con penas máximas los delitos citados. Años 1937-39. Son notables los procedimientos contra el P.O.U.M. y contra la llamada «quinta columna” valenciana.

Documentos de los Tribunales Militares Permanentes del Ejército del Centro: Contiene los sumarios y causas de dichos tribunales, los informes y normas emitidos por las asesorías jurídicas de los mismos, y algunos documentos de la Sección de Asesoría y Justicia, de la Subsecretaría del Ministerio de Defensa. Años 1936-39.

Audiencias y Tribunales Populares: Recoge esta subserie los sumarios y causas de los Tribunales Populares, Jurados de Urgencia y Jurados de Guardia establecidos en las diversas provincias, a partir del mes de agosto de 1936, y los procedimientos vistos en las Audiencias provinciales a partir de agosto de 1937. También se conserva documentación de las Audiencias Territoriales de la zona republicana, en las que predominan sobre todo los expedientes gubernativos y de organización de la justicia en el territorio de su competencia.

Merecen mención por su abundancia los procedimientos que se conservan de las actuaciones de los Tribunales Populares de Madrid y de Alicante. Años 1936-39.

Subserie del Ministerio de Justicia: Recoge informaciones abundantes sobre las comisiones judiciales depuradoras creadas en diciembre de 1936, y sobre su actividad; expedientes personales de Magistrados, Jueces, Fiscales y de otras escalas inferiores al servicio de los Tribunales; informes sobre tribunales y su funcionamiento; presupuestos del Ministerio; Decretos y Ordenes; y una correspondencia con la Fiscalía General de la República en torno a sucesos extraordinarios, de repercusión en la vida social y en el orden ciudadano, de enorme interés en estos años de guerra.

Se incluyen también en esta Subserie los fondos escasos, procedentes de la Consellería de Justicia, de la Generalitat de Cataluña.

Documentos del Tribunal Supremo: Contiene la tramitación de indultos, expedientes personales y algunos sumarios especiales como el instruido por la caída de Vizcaya, Santander y Asturias. Se guardan también las Memorias de la apertura de Tribunales de los años 1934 a 1936.

Mención especial merecen las diligencias sumariales ordenadas hacer a todas las Audiencias por la Fiscalía General de la República por una 
orden del 28 de septiembre de 1937 . Se solicitaba en esta orden recoger antecedentes sobre:

La situación social, política y administrativa previa a la sublevación del 19 de julio; Un informe sobre la actuación de las autoridades gubernativas, judiciales y militares en julio de 1936; Referencia a los sucesos acaecidos durante la primera semana del movimiento insurreccional; Informe sobre bombardeos nacionales a la población civil; Informe sobre las actuaciones de los tribunales de Justicia y estadística de sus resoluciones; Situación de los registros notariales, parroquiales, de la propiedad, registro civil, etc.

Todos estos documentos producidos por el Gobierno e Instituciones republicanas se integraron en el Archivo de la Causa General, a partir de 1940, para servir de prueba en la investigación llevada a cabo por el régimen de Franco. Hoy son una fuente documental de primera mano para conocer la República durante la Guerra Civil, bajo un prisma múltiple?

\section{C) El fondo de «Repatriaciones»}

La Causa General posee entre sus fondos copias de más de 50.000 informes emitidos desde la Dirección General de Seguridad en respuesta a las solicitudes que desde el extranjero hacian los españoles emigrados para volver a España.

El marco cronológico de estos informes abarca desde 1945, fecha en que se crea la Sección de Repatriaciones (dentro de la Dirección General de Seguridad) hasta 1969.

La razón de la existencia, dentro del archivo de la Causa General, de estas copias de informes policiales se explican por dos razones:

a) Por la inevitable cooperación policial a la incoación del procedimiento de la Causa General.

b) Por la presencia de un fiscal de la Causa General en una Comisión interministerial, creada con fecha de 10 de marzo de 1949, para apoyo de la Sección de Repatriaciones y para dictaminar sobre las peticiones de repatriación formuladas. El Director General de Seguridad era quien en

\footnotetext{
Una explicación más abundante del contenido de los fondos puede verse en "Justicia en Guerra". Jornadas sobre la Administración de Justicia durante la guerra civil española: Instituciones y fuentes documentales. Ministerio de Cultura. Madrid, 1990.Páginas 441-482.
} 
última instancia daba su conformidad a los dictámenes de la Comisión o los elevaba al conocimiento y resolución del Consejo de Ministros.

Estos informes reflejan la disposición del Gobierno español frente a los exiliados y dan una serie de datos de gran interés sobre la situación de los españoles emigrados tras la guerra civil.

\section{FONDOS PROCEDENTES DE LA ADMINISTRACIÓN CENTRAL}

Tres son los Departamentos ministeriales que contienen documentos de Guerra Civil y Postguerra en la Sección de Fondos Contemporáneos del Archivo Histórico Nacional: el Ministerio del Interior, el Ministerio de Hacienda y la Presidencia del Gobierno.

\section{Fondo del Ministerio del Interior}

Desde el mes de diciembre de1986 se viene recibiendo periódicamente envíos de la Dirección General de Policia, conteniendo expedientes de personas que fueron investigadas, desde la antigua Dirección General de Seguridad, por actividades políticas contrarias al Régimen de Franco.

La ley de amnistía de 15 de octubre de 1977, por la que se eliminan los antecedentes penales y notas desfavorables en los expedientes personales, procedentes de actos o faltas realizadas con intencionalidad política, determinó la entrega al Archivo Histórico Nacional de todos aquellos expedientes sobre los que la ley de amnistía ejerce su acción.

No entro en el análisis del fondo, pero sí interesa subrayar el enorme valor que muchos de estos expedientes tienen para el conocimiento de la actividad de los partidos y asociaciones políticas bajo la dictadura de Franco.

Es oportuno mencionar aquí el esfuerzo desarrollado por la Sección de Archivo Histórico de la Dirección General de Policía, encargada de transferir al Archivo Histórico Nacional todos los expedientes que caen bajo la ley de Amnistía de 1977, y que podrán ser objeto de más amplios estudios, cuando no pesen sobre ellos las limitaciones que impone el principio constitucional de respeto a la intimidad personal.

Igualmente es oportuno mencionar aquí el alto valor que puedan tener para la investigación histórica del periodo de guerra los expedientes policiales abiertos en las Jefaturas Superiores de Policía, durante los años 1936- 
39, particularmente en la Zona nacional, por la razón evidente de que estas jefaturas siguieron unas directrices de actuación impuestas por el régimen de Franco y no las marcadas por la Dirección General de Seguridad que quedó en Zona Republicana ${ }^{3}$.

\section{Fondo del Ministerio de Hacienda}

Entre los años 1960 y 1962 el Ministerio de Hacienda remitió al Archivo Histórico Nacional más de 24.000 legajos y más de 15.000 libros. Dentro de este amplio volumen, vale la pena destacar dos fondos de la época de Guerra Civil: uno sin inventariar, formado por los documentos de la Comisión interministerial liquidadora de CAMPSA-GENTIBUS, CEA y CLUEA; otro, correspondiente a la Caja General de Reparaciones y que goza ya de un inventario para consulta de los investigadores.

A) El Archivo de la Comisión interministerial liquidadora de C.A.M.P.S.A.GENTIBUS, C.E.A. y C.L.U.E.A.

Contituido por 1.100 legajos y 416 libros, recoge los documentos de estas tres instituciones nacidas durante la Guerra Civil (1936-39) con distintas finalidades: CAMPSA-GENTIBUS canalizó, por mandato del Gobierno Republicano, todas las importaciones y exportaciones realizadas desde mediados de 1937 hasta el fin de la guerra; C.L.U.E.A. fue un organismo sindical, integrado en la Unión General de Trabajadores y en la C.N.T., que intervino y exportó la cosecha naranjera en Levante durante 1936-37; C.E.A. (Comisión Exportadora de Agrios) fue un organismo gubernamental, que sustituyó al anterior, de 1937 a 1939, para canalizar la exportación naranjera.

Terminada la guerra, los archivos de estas instituciones fueron incautados por el gobierno de Franco, creándose al tiempo una Comisión interministerial que tuvo por objetivo recuperar mercancias y dinero, correspondientes a transacciones comerciales aún no finalizadas. Esta Comisión terminó sus trabajos en 1950.

\footnotetext{
3 Las Jefaturas Superiores de Policia dependiente de la Dirección General de Policía radican en Barcelona, Bilbao, La Coruña, Granada, Oviedo, Palma de Mallorca, Las Palmas, Sevilla, Valencia, Valladolid y Zaragoza.
} 
Los documentos que se conservan hacen mención a la contabilidad de estas entidades, magnitudes de mercancias transportadas, cambio de moneda, correspondencia con las diversas delegaciones en el extranjero, envíos de viveres y material de guerra, problemas de Aduanas, fletes, etcétera.

Para utilizar estos documentos sólo cuenta el Archivo con una relación muy somera, realizada en 1950 por el Archivo Central del Ministerio de Hacienda, por lo que resulta difícil valorar en profundidad el interés de estos documentos.

\section{B) El archivo de la Caja General de Reparaciones}

El 23 de septiembre de 1936 el Ministro de Hacienda Juan Negrín firmaba un Decreto por el que se creaba la "Caja General de Reparaciones de Daños y Perjuicios de la Guerra, con cargo a las responsabilidades civiles de los partícipes en el movimiento sedicioso".

En estas breves líneas se contienen los dos grandes objetivos que se perseguian al crear este nuevo organismo: reparar "los daños causados por la rebelión" y aplicar a este fin "los bienes de los criminalmente responsables del movimiento sedicioso que ha atacado la legalidad constituida".

Muchos y amplios eran los objetivos sociales de la Caja, acordes con una situación de guerra que inesperadamente habia de durar casi tres años y que iba a desbordar por completo todas las previsiones.

Una enumeración de sus amplios objetivos queda plasmada en la Memoria que su Dirección General editó en octubre de 1936, con motivo de la constitución de su Junta Rectora. Dice así:

“1. Reparaciones de daños diversos. Auxilios.- Quedarán adscritos a estos servicios, todos aquellos auxilios y reparaciones sin clasificación determinada $y$, por tanto, que, debido a su indole, no encajan en la caracteristica de los servicios que a seguido van a mencionarse.

2. Créditos o anticipos a industrias, determinados por exigencias de la guerra civil o por estar a disposición de la Caja.- Ha de darse sin duda el caso, de que para la exigencia de responsabilidades civiles derivadas de sentencias dictadas por el Tribunal Popular, tenga la Caja que proceder a la incautación de industrias, en las que la Caja, supliendo la actuación financiera del expropiado, cuide de habilitar los fondos necesarios para la buena marcha de aquellos que lo necesiten, evitando quebrantos a la Economía en general y a los trabajadores de esas industrias en particular.

3. Auxilios, créditos o anticipos sobre fincas urbanas determinadas por la guerra.- Comprende este servicio tres características distintas: 
a) Cuando se trata de indemnizar a particulares o corporaciones afectas a la situación, por quebrantos sufridos en su propiedad urbana a consecuencia de la guerra.

b) En los casos en que el auxilio lo sea para reparar daños de guerra o bien para conservación y mejora de fincas urbanas de las incautadas en provecho de la Caja.

c) Si el crédito, anticipo o auxilio se aplica a la continuación de cualquier finca urbana en construcción, incautada en favor de la Caja.

La Dirección General de la Caja estima que las Juntas Provinciales administradoras de fincas urbanas abandonadas deben depender de esta Dirección.

4. Auxilios, créditos o anticipos agricolas a favor de las fincas incautadas por la Caja o determinados por la guerra.- Al igual de lo que hemos dicho con respecto a las industrias incautadas, es más que posible el que se plantee la necesidad de acudir con créditos o anticipos en defensa de las propiedades agrícolas incautadas, como así también auxiliar o prestar a aquellos propietarios afectos a trabajadores agrícolas las cantidades necesarias para hacer frente a aquellos quebrantos o dificultades de que la guerra los haya hecho victimas

Con motivo de la creación de la Caja, se apuntaba por el Gobierno la duda de que los bienes de los criminalmente responsables del movimiento sedicioso, que ha atacado la legalidad constituida de nuestro pueblo, no fueran suficientes para enjugar los cuantiosos daños materiales que ha de soportar el pais con motivo de la guerra.

Al establecerse que habian de descansar sobre la responsabilidad civil de los facciosos, (tomaran parte directa o indirecta en el movimiento), los daños materiales producidos por sus actos, es evidente que se pensaba en que los bienes de éstos, especialmente los rústicos, contribuian en gran escala a la realización de los objetivos que se le habian fijado a la Caja, para que la Economía nacional no se pudiera ver privada de los elementos que necesitase para sostener la guerra ahora, y para la más amplia reconstrucción de la economia, después.

Es por lo tanto, una cuestión de eficacia, de ser o no ser para la Caja, la que mueve a la Dirección General de la misma a estimar que las Juntas calificadoras rústicas constituidas en cada término municipal para formar las relaciones de propietarios complicados directa o indirectamente en la insurrección, así como las Juntas provinciales calificadoras encargadas de resolver las incidencias y cuestiones de competencia que se ofrezcan en la aplicación del Decreto del Ministerio de Agricultura, de 7 de octubre corriente, deben depender de la Caja de Reparaciones por daños ocasionados en la guerra civil.

Con ello se daría estado oficial a las incautaciones de fincas rústicas o agro-pecuarias, con carácter definitivo, adscribiéndolas con toda clase de garantias a los fines de la Caja, que son únicos, y tan vastos que no consentirian de ningún modo la amputación de casi toda la gran propiedad española, hoy incautada por las organizaciones obreras y partidos políticos, así como también por Corporaciones oficiales, volumen cuantioso de fincas que no podrían ser seleccionadas del acervo del fondo de la Caja de Reparaciones, sin que este cercenamiento ocasionara una limitación en la obra de reparaciones por los daños ocasionados en la guerra, que le ha sido asignada como un objetivo nacional, de alto interés patrio. 
5. Necesidades perentorias de la población civil Sostenimiento de refugiados. - La Caja de Reparaciones para poder centralizar su acción y cumplir plenamente la misión que le confiere el Decreto, entiende la Dirección General, que todos los organismos de Estado que cumplen en la actualidad esas atenciones deben revertir a la Caja, al objeto de unificar la acción del organismo, dándole mayor eficacia por tanto".

Hasta aquí la enumeración de objetivos sociales, quizás extremadamente ambiciosos pues pretendía incluir en la esfera de la Caja de Reparaciones a las Juntas Provinciales administradoras de Fincas Urbanas abandonadas, y a la Juntas Provinciales calificadoras rústicas, creadas por el Ministerio de Agricultura para hacerse cargo de las tierras pertenecientes a propietarios complicados en la insurrección.

El archivo que se conserva en la Sección de Fondos Contemporáneos del Histórico Nacional apenas incluye, en efecto, referencias al control efectivo por la Caja de las Juntas calificadoras rústicas que debieron de quedar bajo la tutela del Ministerio de Agricultura.

Las fuentes económicas para cubrir estos objetivos sociales fueron varias.

En primer lugar un crédito de 25 millones de pesetas "concertado libremente por el Ministerio de Hacienda con la Banca y con la garantía inmediata del Estado" (Artículo $2^{\circ}$ del Decreto de 23 de septiembre de 1936).

En segundo lugar la obligación perentoria de «todas las entidades bancarias, organismos públicos, Corporaciones y Asociaciones políticas o sindicales, que hayan procedido a intervenciones o incautaciones de bienes", a ponerlos a "disposición de la Caja", en el lugar que esta determine, en el plazo máximo de quince días. (Artículo $9^{\circ}$ del Decreto de 23 de septiembre de 1936).

Se trataba de integrar de este modo, un proceso revolucionario surgido el 18 de julio y que adquirió fuerza legal con el gobierno de Largo Caballero, creando un Frente Popular de partidos y sindicatos.

Hay muchos documentos en el Archivo de la Caja referentes a este proceso integrador, por el que los Comités provinciales del Frente Popular entregan a la Caja de Reparaciones muchos bienes incautados, de forma provisional, a posibles colaboradores con la sublevación del 18 de julio.

Una tercera fuente de financiación de la Caja la constituyeron "los bienes de las personas inmersas en responsabilidad civil a consecuencia de su participación directa o indirecta en el movimiento sedicioso". (Artículo 3을 del Decreto del 23 de septiembre de 1936). 
La fijación de responsabilidades civiles correspondió en un primer momento a una sección Especial del Tribunal Popular de Madrid para luego recaer en el Tribunal de Responsabilidades Civiles creado el 6 de octubre de 1936, y que tuvo una estrecha relación con la Caja pues ella se encargaba del cumplimiento de cada una de sus decisiones, "quedando a disposición de la misma Caja los bienes incautados o embargados" por el Tribunal.

Las competencias del Tribunal en este sentido fueron muy amplias pues podía acordar no sólo el embargo de bienes, siguiendo las leyes procesales, sino también «la retención provisional de los saldos en cuentas corrientes, Cajas de Ahorros, depósitos de dinero y valores en toda clase de establecimiento de Créditos, de las personas sobre las cuáles hubiese indicios racionales de participación en el movimiento sedicioso". Igualmente la retención provisional podía extenderse a los bienes de aquellos «españoles que abandonaron su residencia habitual para instalarse en territorio rebelde". (Artículo 4ํㅡㄹ del Decreto del 23 de septiembre de 1936).

Para cumplir estas funciones la Caja contó con un estatuto especial: se prohibió a la Banca la concesión de créditos o auxilios, cuya finalidad fuera competencia de la Caja; se prohibió a cualquier autoridad u organización política que no fuera la Caja, la incautación directa de bienes de cualquier persona o Asociación que prestara apoyo a los sublevados; se declaró suspendido el secreto de Contabilidad y Correspondencia mercantiles (establecido por el Código de Comercio) en todas las actuaciones del Tribunal de Responsabilidades Civiles y de la Caja de Reparaciones; por fin se concedió a este organismo el control de todos los efectos bancarios incautados, que quedarian en la misma entidad financiera donde estaban depositados, a disposición de la Caja, y ésta con facultad de realizar gratuitamente sus operaciones de pago.

\section{Mecanismos y cauces de actuación de la Caja de Reparaciones}

Copio íntegramente algunos párrafos de la Memoria que la Dirección General de la Caja editó en octubre de 1936 y que refleja, de acuerdo con el Decreto de creación, los cauces utilizados en la actuación de la Caja, así como los organismos que cooperaban con ella.

"Los Comités provinciales del Frente Popular, mediante el control de la autoridad provincial, se dirigen en sus denuncias al Tribunal Popular. Este, después de sustanciar las mismas, empleando, si para ello fuese preciso, a los Comisarios de Investigación, dirige a la Caja de Reparaciones el resultado de sus actuaciones por medio de la sentencia recaida en orden a la 
responsabilidad civil de los denunciados. Es entonces cuando la Caja de Reparaciones, comunicando a los Comités Provinciales del Frente Popular la sentencia recaída, empieza a actuar, caso de que la sentencia sea condenatoria, utilizando, si preciso fuera, a sus Delegaciones o Representantes Provinciales. Todo esto en cuanto a la interpretación exacta de lo que el Decreto dispone.

Ahora bien: La Dirección General de la Caja entiende que el procedimiento apuntado, al dejar sin control a la misma, por la actuación directa cerca del Tribunal por parte de los Comités Provinciales del Frente Popular, no responde al sentido práctico que ha de acompañar en todo momento a sus actividades y por tanto considera, que el procedimiento a seguir debiera ser el siguiente:

Previa la intervención de la Autoridad municipal, en vez de provincial, los Comités Provinciales del Frente Popular, dirigirán, a través de la Caja de Reparaciones, al Tribunal Popular especial que funcione en Madrid, sus denuncias sobre elementos facciosos que hayan motivado incautaciones o bien que aconsejen el efectuarlas. La Caja de Reparaciones al recibir la denuncia para su trámite al Tribunal, dispondrá inmediatamente que, hasta tanto recaiga sentencia sobre la misma, los bienes del denunciado queden retenidos a su nombre, cuando la incautación se haya ya realizado o bien, cuando aún no exista incautación, el bloqueo de esos bienes del denunciado, en espera de la sentencia. Recaída sentencia sobre cualquier denuncia podrá entonces la Caja, comunicándolo a los denunciantes, declarar firme la retención o apropiarse definitivamente los bienes bloqueados, cuando aquella sea condenatoria y devolver los bienes o levantar el bloqueo, según los casos, cuando la sentencia lo sea con carácter absolutorio.

Este procedimiento que se sugiere, a más de permitir el control de todas las demandas que al Tribunal vayan, facilitará el que los bienes objeto de sujección a la responsabilidad civil del denunciado se hallen ya bajo la custodia directa de la Caja. Aparte esto, el deseo continuo que ha de mover a nuestro Organismo a encontrar las mayores fuentes con que nutrir sus fondos, posibilitará el que las Delegaciones Provinciales de la Caja, al margen de lo que efectúen por sí mismos los Comisarios de Investigación del Tribunal, puedan complementar las informaciones recibidas con la denuncia, indicando bienes de los inculpados cuya existencia haya escapado a los denunciantes.

He aqui expuesto en breves líneas lo que a la Dirección General le parece como imprescindible en orden a la recepción y tramitación de las denuncias al Tribunal Popular especial».

De lo hasta aquí recogido merecen destacarse los siguientes puntos: la importancia que se deseaba atribuir en las incautaciones a las autoridades municipales; la necesidad de un rápido establecimiento de Delegaciones Provinciales de la Caja en todo el territorio nacional, reducidas de hecho al territorio de dominio republicano; la existencia de unos comisarios de investigación directamente dependientes del Tribunal de Responsabilidades Civiles y que colaboran en la investigación de "supuestos facciosos"; y la importancia de los Comités Provinciales del Frente Popular presentes en todas las actuaciones ante el Tribunal, avalando las denuncias de las Autoridades municipales. 
Un esquema gráfico de la actuación de la Caja a tenor de lo que muestran los documentos de su archivo podrá ser el siguiente:

Fase de

Investigación
Fase de

Denuncia y Juicio

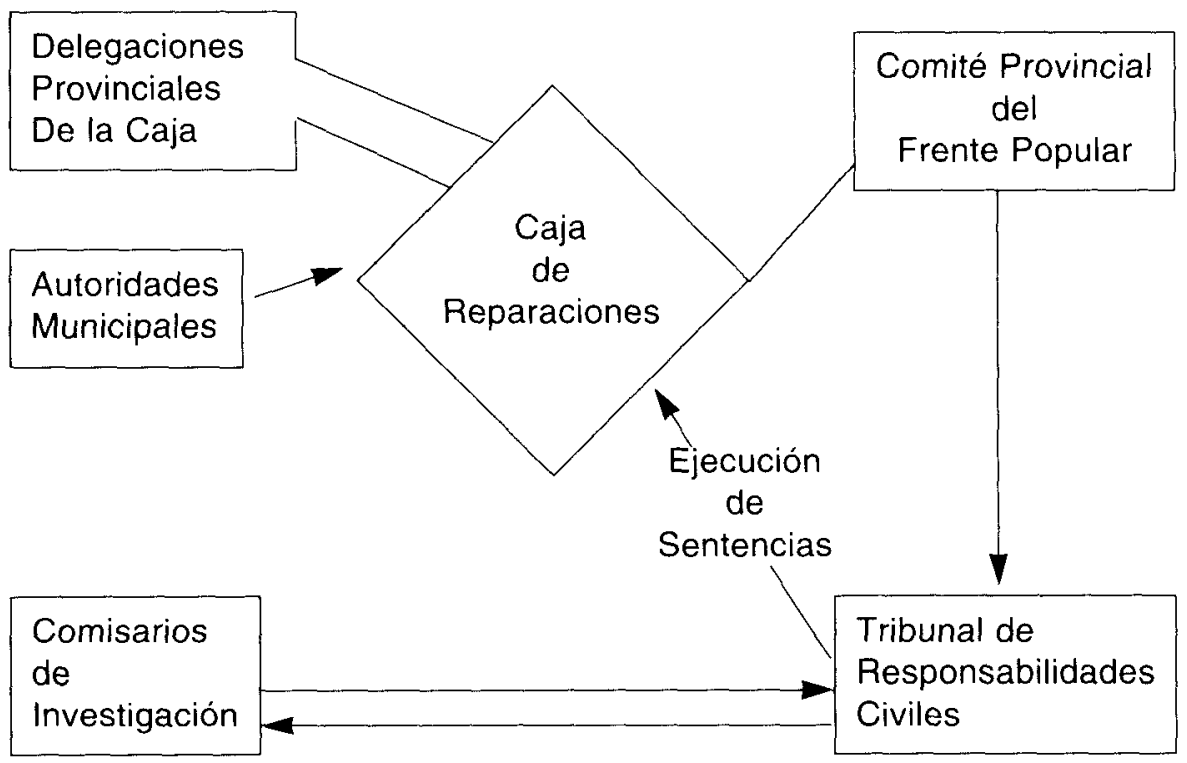

La organización de la Caja General de Reparaciones

La máxima autoridad de la Caja radicaba en una Junta, más adelante llamada Consejo ejecutivo que presidía un Delegado del Gobierno nombrado a propuesta del Ministerio de Hacienda. Dicho Consejo lo integraban un representante de cada uno de los partidos del Frente Popular, el Interventor General de la Administración del Estado, el Gobernador del Banco de España, un banquero y un miembro de la Federación de Trabajadores de Crédito y Financias. (Artículo 10 del Decreto de 23 de septiembre de 1936).

Este Consejo Ejecutivo se encargaba de elaborar la legislación y toda la normativa relacionada con la Caja, para lo que contaba con los informes de la Asesoría Jurídica que mencionaremos más adelante. De hecho la 
actuación de la Caja General de Reparaciones planteó numerosos problemas relativos a conflictos y deslindes de competencias de los que cito algunos más importantes: conflictos de las Delegaciones Provinciales de la Caja con los Comisarios de Investigación, directamente dependientes del Tribunal de Responsabilidades civiles; entre el servicio de Retenciones y el de Investigación político-económica muy afines en sus funciones; entre el Ministerio de Agricultura y la Caja por el problema generado por las incautaciones de tierras; entre la Caja y la Junta Central del Tesoro Artístico por problemas relacionados con la incautación de obras artísticas.

El Director General: personalizaba al organismo en su representación y le correspondia la firma de todos los documentos que hubieran de someterse a la consideración del Ministerio de Economía y Hacienda, o fueran dirigidos a otras dependencias oficiales o particulares.

A él estaban subordinados todos los funcionarios de la Caja y debía firmar todos los expedientes tramitados por esta cuando se produjera una resolución definitiva.

Presidia el Comité Ejecutivo, era nombrado a propuesta del Ministerio de Hacienda y contaba con un Vice-Director en el que podía delegar todas las atribuciones que deseara.

Don Amaro del Rosal Díaz, destacado dirigente del partido socialista, fue nombrado Director General el 29 de septiembre de 1936 y ostentó el cargo hasta el final de la guerra.

La Secretaría General fue otro de los organismos claves, pues le concernía todo cuando afectaba al régimen interior de la Caja. Don Eduardo Ruiz Gajá fue nombrado para este cargo el 15 de octubre de 1936 y permaneció en él hasta el fin de la Guerra.

A la Secretaría estaban agregados los siguientes servicios:

Registro General: control de entrada, distribución y salida de documentos.

Personal y Habilitación: nombramientos, ceses, traslados, y expedientes personales de los empleados de la Caja.

Archivo: para los expedientes ya tramitados.

Servicio de Estadística: recogía las noticias que afectaban a la política de la Caja; llevaba un fichero de "facciosos" con todos los datos de interés sobre bienes, y la estadística de actividades de la Caja.

Servicios de Expediciones y almacén: la Caja de Reparaciones centralizó los objetos incautados en varios almacenes repartidos por el 
territorio republicano y a ellos se dirigían periódicamente expediciones, organizadas por la propia secretaria. Jaén, Valencia, Barcelona y Madrid fueron los puntos de concentración, señalando el Paseo de Gracia, 107 y la Plaza de Cataluña, 15 para Barcelona; y en Madrid diversos puntos como: el Museo del Prado, Museo de Arte Moderno, los depósitos del Banco de España, la calle Goya, no 87 , calle Fomento, no 9 y la calle Alcalá, $n^{\circ} 15$.

El ingreso de los objetos incautados solía correr a cargo de la Policía, del Ejército o del servicio de incautación y en todos los almacenes había un registro de entradas y salidas de objetos.

La conservación de los mismos había de hacerse de acuerdo con el Servicio Técnico, creado para facilitar las relaciones con la Junta de Protección del Tesoro Artístico Nacional.

El Servicio Técnico emitía un primer dictamen sobre los objetos de valor histórico y artístico; controlaba las entregas de los mismos a la Junta de Protección del Tesoro Artístico; dirigía la conservación de aquellos objetos de valor que habían de ser custodiados por la Caja e intervenía en los talleres de manipulación de joyas para evitar especulaciones o destrucciones de obras de arte.

La Asesoría Jurídica de la Caja, a cargo de un abogado del Estado emitia dictamen en temas que se le sometian a propuesta de cualquier Servicio y previa conformidad del Vicedirector.

Asi mismo se responsabilizaba de las relaciones de la Caja con el Tribunal de Responsabilidades civiles, emitiendo informes y guardando copia de todas las sentencias del mismo.

Tesoreria: Contaba el movimiento del dinero y se hacía cargo de la custodia de los metales y piedras preciosas incautadas; para esto último una sección de joyería tasaba y valoraba las piezas, siempre bajo la supervisión ya dicha del Servicio Técnico.

Intervención y Contabilidad: todas las cuentas y los presupuestos de la Caja pueden estudiarse a través de los documentos de este servicio, tal como se contienen en el Archivo que aqui se presenta.

Servicio Financiero: llevaba el control de todos los valores y títulos mobiliarios que ingresaban en la Caja, por incautación, encargándose de negociar con ellos y de cobrar los intereses que pudieran corresponderles, subrogando en sus derechos a los antiguos propietarios de los mismos. Es inmensa su correspondencia con todos los bancos del país y es uno de los servicios que mejor funcionó en la Caja, en parte también porque los 
valores mobiliarios permanecieron depositados en los bancos. Es fuente inagotable para conocer las inversiones en Sociedades Anónimas y por ello motivo de restricciones en la consulta que no sea por motivos de investigación histórica.

Los tres servicios que a continuación se citan dependian directamente de la Vice-Dirección y son los siguientes:

Inspección: Mantenía las relaciones de la Caja de las Delegaciones Provinciales y los Comisarios de Investigación unificando la acción de todos ellos.

Servicio de Retenciones: Tramita los siguientes expedientes: retención de cuentas corrientes y valores de supuestos "facciosos"; apertura de cajas de alquiler en bancos; entregas a la Caja de objetos y valores incautados por Consejos Municipales y comités antifascistas; retenciones provisionales de objetos y valores pertenecientes a personas sospechosas; expedientes de devolución, con informe sobre la procedencia de esa medida.

Cerca de diez mil expedientes de esta clase se conservan en el archivo y pueden ser suficientes para adquirir una idea del proceso seguido por la Caja en su función reparadora de daños.

Servicio de investigaciones político-económicas: Buscaba datos sobre las actividades y situación económica de supuestos rebeldes. Debía estar muy conectado con el servicio de Retenciones y ello originó frecuentes conflictos de competencias.

Esta organización que aquí se describe no fue definitiva hasta 1937. (Leg. 5375, Exp. 2) Consultando la Memoria, otras veces citada, impresa en octubre de 1936 se habla de una Sección Agraria (para controlar los valores rústicos), de una Sección Urbana (para controlar las propiedades urbanas incautadas), y de una Sección de Industria y Comercio (para controlar las empresas incautadas), y de una Sección de Industria y Comercio (para controlar las empresas incautadas), todo ello muestra de unos objetivos mucho más ambiciosos que no pudieran desarrollarse al chocar con las competencias de otros Ministerios, que estos no quisieron entregar en manos de la Caja.

Asi se explican también los amplios objetivos sociales y de ayuda que la Caja pensó en desarrollar, pero de los que hubo de desistir por incapacidad económica y falta de medios. 
La Comisión Liquidadora y la recuperación del archivo de la Caja

Terminada la guerra civil, en marzo de 1940, el gobierno de Franco creó una Comisión liquidadora de la Caja de Reparaciones que tenía por objeto "levantar las retenciones de saldos en los bancos y de depósitos de títulos, acordados por el gobierno marxista", entregando a sus anteriores propietarios todos los valores y objetos retenidos por la Caja.

La Comisión dependía del Ministerio de Hacienda, estaba presidida por Don Luis Vallejo Tirado, abogado del Estado y en ella participaban como vocales un magistrado y un fiscal, representantes del Ministerio de Justicia.

La Comisión creó dos secciones: una de valores y documentación y otra de objetos, que tenían como función abrir expediente de devolución, de todos aquellos bienes reclamados por personas y entidades contra las retenciones de la Caja General de Reparaciones.

El Archivo que guarda todas estas actuaciones, y que está incorporado al de la Caja General de Reparaciones, incluye unos 1.400 expedientes de devoluciones, entregándose el resto de objetos y bienes no reclamados a un juzgado gubernativo de Madrid, creado por tal efecto (Artículo $7^{\circ}$ del Decreto de 9 de marzo de 1940).

Una de las funciones primeras de la Comisión fue recuperar, en la medida de lo posible, los documentos generados por la antigua Caja de Reparaciones, que justificaran la incautación y la verdad de las reclamaciones. El Archivo de la Caja apareció recogido en su mayoría en el número 15 de la Plaza de Cataluña, en Barcelona; y se completó con los documentos y objetos de arte encontrados en la calle Medinaceli, 6 y 8 de Madrid, antigua sede de la Comisaría General del Servicio de Defensa del Patrimonio Histórico Nacional.

Más de 600 bultos fueron recogidos entre papeles, objetos, títulos y valores, que fueron trasladados a las dependencias del Ministerio de Hacienda, en Madrid.

Sin entrar en una valoración, imposible sin un estudio reposado de los documentos, sí se puede afirmar que este archivo de la Caja y de la Comisión liquidadora contiene fuentes indispensables para conocer la labor incautadora de la República con "los rebeldes", la naturaleza de las incautaciones (joyas, muebles, cuadros, títulos bancarios, metales preciosos, inmuebles urbanos, etc.), la utilidad que la República dió a las mismas, y el destino final de lo incautado al llegar la derrota de 1939. 
Terminada la actividad de la Comisión Liquidadora en junio de 1942, los documentos pasaron a las dependencias del Archivo Central del Ministerio de Hacienda y en 1961 al Archivo Histórico Nacional, Sección de Fondos Contemporáneos.

Sólo una observación final: los documentos y los libros producidos por la Caja de Reparaciones y la Comisión liquidadora correspondiente, quedaron mezclados con otros documentos y libros procedentes de otras dependencias de la Hacienda Pública y al ser remitidos al Archivo Histórico Nacional un pequeño número de libros quedó en el Archivo Central de Hacienda, anomalía que queda recogida en el Inventario que está ya a disposición de los investigadores en el Archivo Histórico Nacional.

\section{El nuevo inventario del Archivo Histórico Nacional}

Recoge una serie de 62 libros y 262 legajos generados por la Caja General de Reparaciones y la Comisión liquidadora, que abarcan desde 1936 a 1942, y que han sido rescatados del fondo general procedente del Ministerio de Hacienda, que tiene un volumen total de más de 13.000 legajos.

Se hace esta indicación para subrayar el trabajo de búsqueda de estos documentos y sobre todo para indicar que no se puede dar como definitivo y cerrado el inventario que aquí se presenta ante la eventualidad de que algún otro legajo pudiera aparecer, producido por la Caja de Reparaciones.

El inventario es somero pues renuncia en muchos casos a la ardua tarea de recomponer los expedientes, pero si se ha tratado de completar con unos buenos indices de materias, lugares, organismos y personas. Junto a los índices de personas se incluyen como apéndices dos relaciones de nombres elaborados en los años cuarenta, siendo archivero del Ministerio D. Antonio Matilla Tascón, y que recogen una abundante información que completa así todo el trabajo realizado por los archiveros del Ministerio y del Archivo Histórico Nacional ${ }^{4}$.

En cuanto a la consultabilidad del fondo es menester advertir a los investigadores que existen muchos datos referidos a personas y que tienen relación con las propiedades, objetos y títulos financieros incautados por la

\footnotetext{
4 El inventario ha sido realizado por Consuelo Durán Cermeño, Julia Pérez Reyes, Pilar Martin-Palomino y $\mathrm{M}^{\mathrm{a}}$ Teresa Fernández Talaya, bajo la dirección de Jesús Gaite Pastor.
} 
República: Son sin duda informaciones de hace más de cincuenta años, pero que tienen que ver con los aspectos económicos personales y rozan el ámbito de la intimidad, por lo que deben respetarse las leyes vigentes sobre este tema, tanto el principio constitucional como las de desarrollo del mismo.

\section{Fondo de la Presidencia del Gobierno}

Recoge 222 legajos entregados al Archivo Histórico Nacional en 1965 por la Dirección General de Adquisiciones y referido a la adquisición de materias primas y productos en su gran mayoría de carácter bélico, procedentes de Alemania, Italia y otros países, con destino a los Ministerios militares. El ámbito cronológico abarca de 1937 a 1950, siempre correspondiente a la administración del gobierno nacionalista.

Esta serie tiene a disposición del público un inventario, redactado por Maria Luisa Conde Villaverde.

\section{ARCHIVOS PERSONALES DE ÉPOCA CONTEMPORÁNEA, EN LA SECCIÓN DE DIVERSOS}

La Sección de Diversos del Archivo Histórico Nacional posee también algunos fondos relacionados con la Guerra Civil y posguerra.

Son, en todo caso, documentos de personas que tuvieron una destacada intervención en la vida pública española de la época y que al cabo del tiempo han depositado sus archivos en este Centro Nacional.

La Sección de Diversos en su apartado de "Archivos familiares y personales" tiene asignada la custodia de estos fondos entre los que comentaremos brevemente los más significativos correspondientes a la época que nos ocupa:

\section{Archivo de Marcelino Pascua}

Entregado el Archivo Histórico Nacional en 1984, no fue de libre acceso hasta 1989. Consta de 18 cajas en las que se recogen datos de gran interés, relativos a su estancia como embajador en Moscú (agosto 1936febrero 1938) y en Paris (marzo 1938-marzo 1939) y a su posterior exilio en Norteamérica. 
En relación con el tema que nos ocupa en estas jornadas valdría la pena citar algunos asuntos de interés preferente:

- Suministros de material bélico a la República.

- El Comité de no intervención y la política europea frente a la guerra de España.

- Relaciones hispano-rusas e hispano-francesas durante la Guerra civil. España y la Sociedad de Naciones.

- El oro de Moscú, el oro español del Banco de Francia y las ventas de oro y monedas por el gobierno republicano al fin de la guerra. 1939).

- La dimisión de Azaña y el reconocimiento de Franco (febrero-marzo,

- La situación de los españoles en Francia, al fin de la guerra y el apoyo a los exiliados.

- La polémica Prieto-Negrín, desde fines de 1938 y el principio del gobierno republicano en el exilio.

- Actitudes en Norteamérica y en las Naciones Unidas ante el gobierno de Franco (1939-1945).

\section{Archivo de Diego Martínez-Barrio}

Este fondo de 26 legajos mantiene todavia algunas restricciones en la consulta, pues debe solicitarse permiso a sus herederos para acceder a los documentos.

Contiene tres bloques de interés:

a) Una abundante correspondencia particular y con los partidos políticos, que llega hasta su fallecimiento en 1 de enero de 1962.

b) Una información extraordinariamente interesante para los sucesos políticos acaecidos entre marzo y mayo de 1936 como testigo de excepción desde su cargo de Presidente de las Cortes: la destitución del Presidente de la República, Alcalá-Zamora; los problemas de Constitución de las Cortes, salidas de las elecciones de febrero de 1936; y la situación de interinidad hasta la formación del gobierno de Casares-Quiroga en mayo de 1936.

c) También son de interés los datos sobre su actuación como Presidente interino de la República española, desde el momento de la retirada de Azaña y toda su actuación en el Gobierno de la República en el exilio de México, donde vivió después de la guerra hasta su muerte. 
Archivo de Vicente Rojo Lluch

Entregado por la familia del general al Ministerio de Cultura, este Archivo quedó depositado (primero en la Sección de Fondos Contemporáneos), finalmente, en la Sección de Diversos en diciembre de 1987.

Consta de 73 cajas y 8 carpetas, referidas fundamentalmente a la época de guerra civil y exilio. Hoy es de libre consulta, pero a través de un microfilm terminado en 1990.

El inventario realizado por D. Angel Rojo, hijo del General, ocupa 466 hojas en su mayor parte dedicadas a la descripción de los documentos correspondientes a la guerra civil, en la que ocupó el cargo de Jefe de Estado Mayor para la defensa de Madrid y desde 1937 Jefe del Estado Mayor del Ejército del Centro y posteriormente Jefe del Estado Mayor del Ministerio de Defensa.

Dentro de los documentos de guerra civil merecen mencionarse varias series documentales.

- Las relaciones oficiales con el Ministerio de Defensa de la República, desde su puesto de Jefe de Estado Mayor (mayo 1937-marzo 1939).

- Los documentos relativos a la organización y plantilla del ejército republicano.

- La correspondencia con los jefes militares y las órdenes impartidas a las distintas unidades.

- Los documentos sobre operaciones militares de especial relieve: Brunete, Belchite, Teruel, batalla del Ebro.

- Boletines de información sobre la Defensa de Madrid y otros artículos de prensa nacional y extranjera, contemporáneos de la guerra española.

- Por fin hay que añadir una "Historia de la Guerra de España", que quedó inédita e incompleta pero que aporta la visión del militar republicano a este período de nuestra historia. Realizada al parecer durante su estancia en el exilio en Bolivia.

\section{Otros archivos}

Sólo quiero citar otros dos archivos personales, depositados en la Sección de Diversos, y que tienen relación con el tema que nos ocupa: 
a) El archivo de Margarita Nelken, avanzada fémina durante la República y la guerra civil: diputada desde 1931 y Medalla de la Sierra y de la Defensa de Madrid. Un símbolo más de la oposición a Franco desde su exilio en México.

b) El archivo de Luis Araquistain, embajador de España en Paris, algunos meses de 1936, y periodista perteneciente al ala izquierda de Largo Caballero. 